Research Article

\title{
The Undrained Characteristics of Tengger Desert Sand from True Triaxial Testing
}

\author{
Xuefeng Li $\left(\mathbb{D},{ }^{1,2}\right.$ Weinan Lu ${ }^{D},{ }^{1}$ Zhigang Ma ${ }^{D},{ }^{1}$ and Ni Tuo ${ }^{1}{ }^{1}$ \\ ${ }^{1}$ School of Physics and Electronic-Electronic Engineering, Ningxia University, Yinchuan 750021, China \\ ${ }^{2}$ Solid Mechanics Institute, Ningxia University, Yinchuan 750021, China \\ Correspondence should be addressed to Xuefeng Li; lixuefeng1928@163.com
}

Received 26 April 2021; Revised 8 June 2021; Accepted 26 June 2021; Published 7 July 2021

Academic Editor: Pengfei Liu

Copyright (c) 2021 Xuefeng Li et al. This is an open access article distributed under the Creative Commons Attribution License, which permits unrestricted use, distribution, and reproduction in any medium, provided the original work is properly cited.

Aimed at the characteristics of aeolian sand under rapid construction conditions in desert geotechnical engineering, a series of the true triaxial undrained test were carried out on the GDS apparatus. The 3D deformation, failure, and other characteristics of the dense sand are obtained. Under the condition of same $p_{c}$, the state transition point where the void water pressure changes from increasing to decreasing appears earlier and leads to enhanced dilatancy with the increase of $b$, which means the enhanced dilatancy of dense sand caused the increase in strength. The results of the same $b$ shows that the void water pressure generally indicates a decrease at low confining pressure and an increase at high confining pressure, indicating that the aeolian sand shows dilatancy at low confining pressure and contraction at high confining pressure. The state transition point increases with the increase of $p_{c}$, but all points tend to the same critical state line and state transition line. When $b=0$, the critical state line is $q=1.57$ $p^{\prime}$, and the state transition line is $q=1.23 p^{\prime}$. When $b=1$, the critical state line is $q=1.24 p^{\prime}$, and the state transition line is $q=1.04$ $p^{\prime}$. The results at same $b$ obtained the unified critical state line and the state transition line. Therefore, the true triaxial test can obtain the unified relationship of void ratio, $p_{c}$ and $b$, which overcomes the fact that the existing test cannot consider the influence of $b$. The test results provide a basis data for the design, construction, and maintenance of geotechnical engineering in Tengger Desert.

\section{Introduction}

The policy of Western development in China has greatly promoted the infrastructure construction in desert areas, and a large number of desert geotechnical engineering will be built [1]; however, the experimental research on aeolian sand is lagging behind. Tengger Desert is the fourth largest desert in China, covering an area of 42,700 square kilometers. Due to its arid nature environment and aeolian characteristics, aeolian sand is characterized by fine particles, irregular morphology, poor surface activity, low water content, and high permeability. Restricted by arid natural environment and underdeveloped social conditions in the west of China, the test results of aeolian sand are scarce, and only a few test results serve the engineering construction, such as the construction of roads [2], railways [3, 4], and power transmission lines $[5,6]$ crossing the desert, and its eco-environmental construction. A targeted research has been done on accidents such as quicksand, collapse, and excessive settlement of the superstructure during construction [7]. The research on the compaction characteristics of subgrade [8-10] shows that the aeolian sand has a high degree of compaction under dry conditions and saturated conditions, so it has the unique characteristics of compaction "bimodal," which provides a dry compaction technology of subgrade construction in the desert area. Aeolian sand is also collapsible, which is attributed to the high content of fine sand and low dry density $[11,12]$. Wang et al. [13] found that the sand collapsibility is indirectly verified by the additional settlement of the sand after wetting. The bimodal characteristics and the collapsibility are two unique properties of aeolian sand obtained from the tests at present. 
However, many other properties of aeolian sand in 3D space, such as the strength, the stress-strain relationship, the dilatancy, and the critical state, have rarely been studied.

In practical engineering, the characteristics of sand are meaningful in 3D stress state $[14,15]$. However, there are relatively few results from triaxial tests of aeolian sand in China. For the true triaxial test of aeolian sand, only Li et al. [16] carried out the drainage test of Tengger Desert sand. For the conventional triaxial test, Deng [17] and Song [18] had carried out static-dynamic tests. Zhang et al. [19], Zhang et al. [20], and Li et al. [21] studied on the freeze-thaw cycle properties. Li and Zhang [22] carried out undrained tests for the $\mathrm{Mu}$ Us Desert sand with different confining pressure. Hao et al. [23] studied the structural strength index of unsaturated sand. The study of Badanagki's [24] undrained test for the Sahara sand states that the shear strength decreases with the increase of relative compaction.

At present, only the true triaxial tests of other types of sand are studied, but the results are relatively few. Choi et al. [25] carried out true triaxial tests for drained and undrained with different stress path. Suits et al. [26] studied the influence of intermediate principal stress on the stress-strain relationships and found that the obvious anisotropy was shown in the sand. Lade and Wang [27] studied the deformation and failure characteristics of sand with the different densities and found that the peak failure of sand was mainly caused by shear bands. For Toyoura sand, Yamada and Ishihara [28] and Yoshimine et al. [29] found that the larger $b$ is, the greater the void water pressure is, which has a greater impact on the deformation. Pan et al. [30] found that triaxial compression and triaxial extension tests show significantly different characteristics and triaxial compression is characterized by shear dilatation but the extension test is dominated by strain softening. For the Fujian standard sand, $\mathrm{Xu}$ et al. [31] found that the $b$-value has little effect on stress ratio, and Li and Yang [32] found that the confining pressure has little effect on the strength of the specimen. For the Ottawa sand, Murthy et al. [33] found that the critical state of the drainage test is the same as the undrained test, and the undrained shear strength increases with the increase of specimen density. For Shanghai sily sand, Hu et al. [34] found that the peak stress is raised with the increase of the confining pressure at failure, but the relationships between shear stress and the $b$-value are complicated. Liang and Ping [35] found that the peak shear stress increases with the increase of $b$ and the void water pressure first increases and then decreases. Therefore, in geotechnical engineering [36] the sand foundation will lose its bearing capacity due to the increase of void water pressure under the condition of instantaneous strong load or cyclic load. So it is necessary to carry out the undrained test.

The research on the strength of subgrade has accumulated some experience, which mainly focuses on highway design, construction technology, and meteorological and hydrological detection in the Tengger Desert area. However, the results of triaxial tests on aeolian sand are seriously lacking, which affect the understanding of its engineering characteristics. Especially because the critical state line of sand is not unique, it is mainly affected by the stress path and anisotropy $[37,39]$. The true triaxial test can be used to study various complex stress paths and the critical state of soil in true $3 \mathrm{D}$ space. In this paper, the true triaxial undrained test of aeolian sand in Tengger Desert is carried out by the British GDS true triaxial apparatus. The deformation, failure, dilatancy, and critical state characteristics of sand are studied with different $b$-values and $p_{c}$. Through the analysis of void water pressure, generalized shear stress, stress ratio, and other mechanical characteristics, the undrained strength of Tengger Desert sand will be explored.

\section{The True Triaxial Equipment}

The British GDS true triaxial apparatus is used (Figure 1) in this paper, which can carry out the static and dynamic quick loading test. As shown in Figures 1 and 2, the specimen is placed in the pressure chamber, and the pressure is applied by the rigid loading plates and flexible loading systems. Rigid loading is controlled by a servo motor and flexible loading is applied by water. The flexible load is controlled by the pneumatic controller. The air pressure controller is connected to the air collector and air pump, indicated by the green line in Figure 1. For more detailed introduction of the loading method, see reference [16].

\section{Test Processes and Schemes}

3.1. Introduction to the Test. The sand is collected from Tengger Desert in the Shapotou area, Zhongwei City, Ningxia Hui Autonomous Region, where is the distribution area of typical aeolian sand. The sand particle size of $0.075 \sim 0.5 \mathrm{~mm}$ accounts for more than $90 \%$. The size gradation and some physical properties of aeolian sand are shown in Table 1. According to the Unified Soil Classification System, Tengger Desert sand is fine sand [40]. The size of the specimen is $75 \times 75 \times 150 \mathrm{~mm}$. According to the method of layering compaction, the cuboid specimen is divided into 10 layers. The relative compaction of the specimen is controlled at 0.7. The weight of the specimen is $1291 \mathrm{~g}$. A dry deposition method is used for the preparation specimen.

The specimen is saturated by two steps: one is head saturation, and another is backpressure saturation. After the backpressure saturation, the void water pressure coefficient $(B)$ is computed. If $B$ reaches more than $95 \%$, the specimen can be considered to be saturated fully. $B$ represents the saturation degree of the specimen, when $B=0$, the specimen is completely dried, and when $B=1$, the specimen is saturated $100 \%$. The consolidation adopts an isotropic method of rigid and flexible combination. The criterion for the end of consolidation is that the change of water volume in the backpressure controller does not exceed $1 \%$ of the total amount within a certain time $(30 \mathrm{~min})$.

In the shearing process, the strain control loading can be adopted to ensure constant $b$-value, and the strain control can also better control the collision of rigid loading. According to the definition of $b$-value, the expression equation (1) of the intermediate principal strain coefficient 


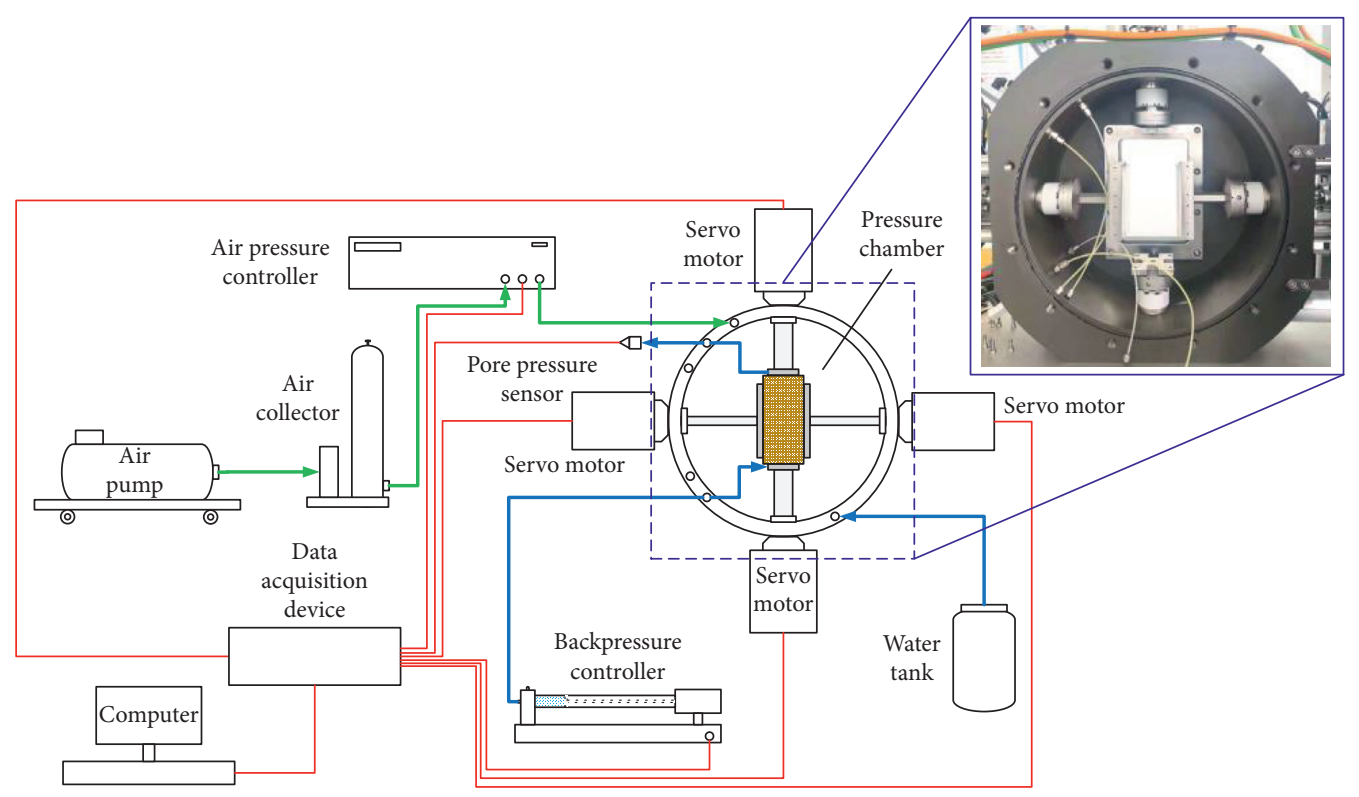

FIgure 1: The true triaxial test system.

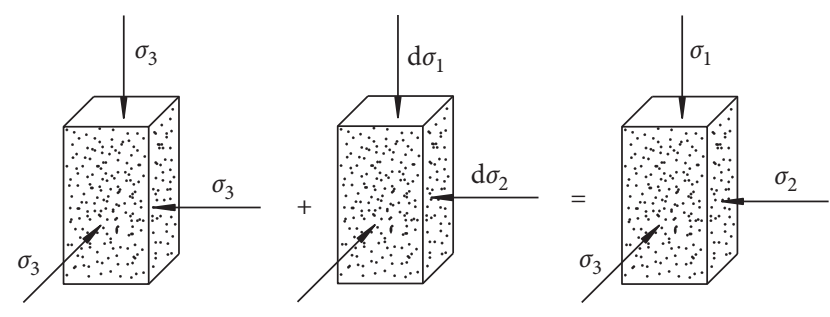

Figure 2: Loading diagram.

$\left(b_{\varepsilon}\right)$ is given. The strain control loading under the condition of constant $b$ can be realized through equations (1) and (2):

$$
b_{\varepsilon}=\frac{\varepsilon_{2}-\varepsilon_{3}}{\varepsilon_{1}-\varepsilon_{3}}\left(0 \leq b_{\varepsilon} \leq 1\right) \text {, }
$$

where $\varepsilon_{1}, \varepsilon_{2}$, and $\varepsilon_{3}$ are the maximum principal strain, the intermediate principal strain, and the minimum principal strain, respectively.

Under the undrained condition, the volume of the soil sample remains unchanged, and the strain satisfies

$$
\varepsilon_{v}=\varepsilon_{1}+\varepsilon_{2}+\varepsilon_{3},
$$

where $\varepsilon_{v}$ is the volume strain.

According to equations (1) and (2), the incremental relation is

$$
\left\{\begin{array}{l}
\mathrm{d} \varepsilon_{1}=\mathrm{d} \varepsilon_{1}, \\
\mathrm{~d} \varepsilon_{2}=b_{\varepsilon} \mathrm{d} \varepsilon_{1}, \\
\mathrm{~d} \varepsilon_{3}=0,
\end{array}\right.
$$

where $\mathrm{d} \varepsilon_{1}, \mathrm{~d} \varepsilon_{2}$, and $\mathrm{d} \varepsilon_{3}$ are the increment of maximum principal strain, intermediate principal strain, and minimum principal strain, respectively. From equation (3), the loading method of constant $b$-value is performed. The loading in the direction of $\varepsilon_{1}$ and $\varepsilon_{2}$ is rigid, and the loading in the direction of $\varepsilon_{3}$ is flexible (Figure 2). The pressure on the flexible surface is a constant, and two rigid plates in equation (3) can be used to control the intermediate principal stress coefficient.

3.2. Test Schemes. Three group schemes are designed in this experiment. The first is to adopt the $b$-values of $0,0.25,0.5$, and 1 , respectively, under the condition of keeping $p_{c}$ equal to $100 \mathrm{kPa}$. In the shearing progress, $b$-value and $p_{c}$ are constant. The stress paths are shown in Figure 3(a).

The second is to adopt $p_{c}$ of $50 \mathrm{kPa}, 100 \mathrm{kPa}, 200 \mathrm{kPa}$, $400 \mathrm{kPa}$, and $800 \mathrm{kPa}$, respectively, with $b=0$. The purpose is to obtain the critical state line, state transition line, and the stress-strain relationship of dense aeolian sand under the undrained condition with $b=0$. The stress paths are shown in Figure 3(b).

The third is to adopt $p_{c}$ of $50 \mathrm{kPa}, 100 \mathrm{kPa}$, and $200 \mathrm{kPa}$, respectively, with $b=1$. The purpose is to obtain the critical state line and state transition line of the aeolian sand under the undrained condition with $b=1$. The stress path is shown in Figure 3(c).

In the direction of $\sigma_{1}$, the speed of strain loading is $0.315 \mathrm{~mm} / \mathrm{min}, 0.315 \mathrm{~mm}$ equivalent to $0.21 \%$ of the height of specimen. The maximum vertical displacement is $37.5 \mathrm{~mm}$, $37.5 \mathrm{~mm}$ equivalent to a maximum $\varepsilon_{1}$ of $25 \%$. In Figure 3 , the horizontal axis and vertical axis are the mean principal stress $p$ and generalized shear stress $q$, which are $p=\left(\left(\sigma_{1}+\sigma_{2}+\sigma_{3}\right) / 3\right)$ and $q=\sqrt{\left(\left(\left(\sigma_{1}-\sigma_{2}\right)^{2}+\left(\sigma_{2}-\sigma_{3}\right)^{2}+\left(\sigma_{3}-\sigma_{1}\right)^{2}\right) / 2\right)}$.

\section{Test Results and Analysis}

4.1. The Stress Path of the Test. The purpose of the tests is to study the strength and the stress-strain relationship of dense sand in the different stress paths space. As designed in the schemes, it is to study the deformation and strength of sand with the same $p_{c}$ and different $b$-values, as well as the stress- 
TABLE 1: The main physical properties of aeolian sand.

\begin{tabular}{lcccccc}
\hline $\begin{array}{l}\text { Maximum dry } \\
\text { density }\end{array}$ & $\begin{array}{c}\text { Minimum dry } \\
\text { density }\end{array}$ & $\begin{array}{c}\text { Moisture content } \\
(\%)\end{array}$ & $\begin{array}{c}>0.75 \mathrm{~mm} \\
(\%)\end{array}$ & $\begin{array}{c}0.75 \sim 0.5 \mathrm{~mm} \\
(\%)\end{array}$ & $\begin{array}{c}0.5 \sim 0.25 \mathrm{~mm} \\
(\%)\end{array}$ & $\begin{array}{c}0.25 \sim 0.1 \mathrm{~mm} \\
(\%)\end{array}$ \\
\hline $1.62 \mathrm{~g} / \mathrm{cm}^{3}$ & $1.36 \mathrm{~g} / \mathrm{cm}^{3}$ & 0.14 & 0.07 & 3.83 & 94.41 & 1.69 \\
\hline
\end{tabular}
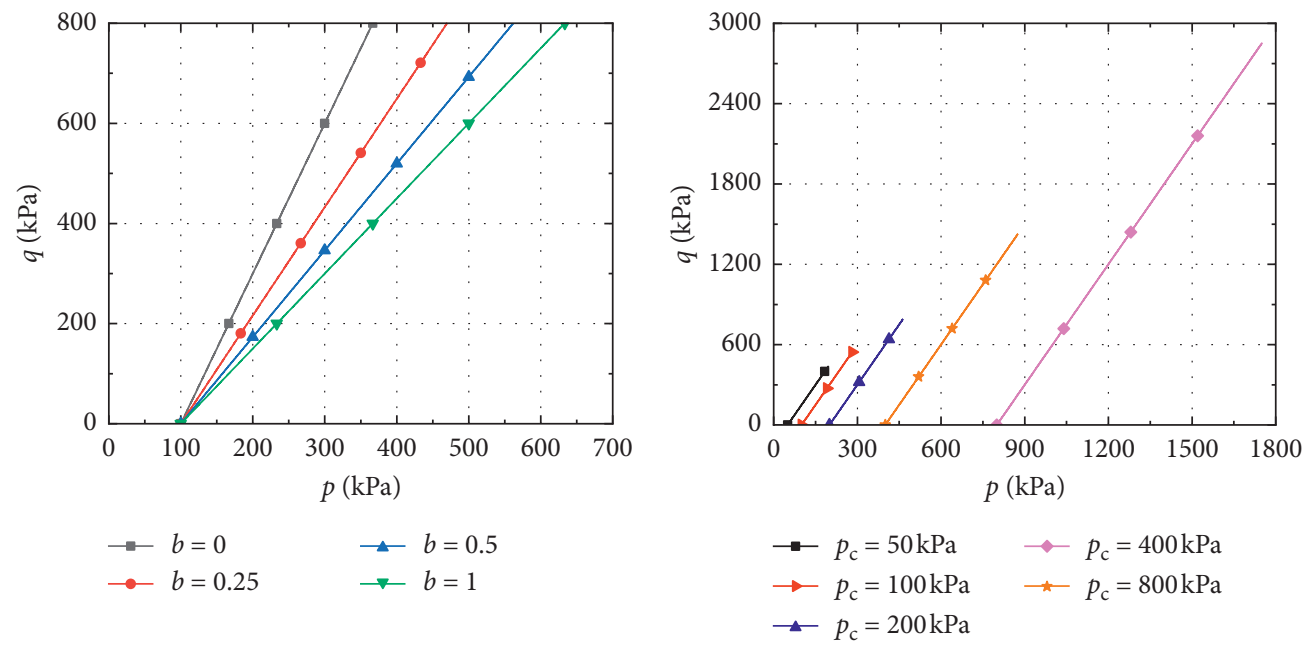

(a)

(b)

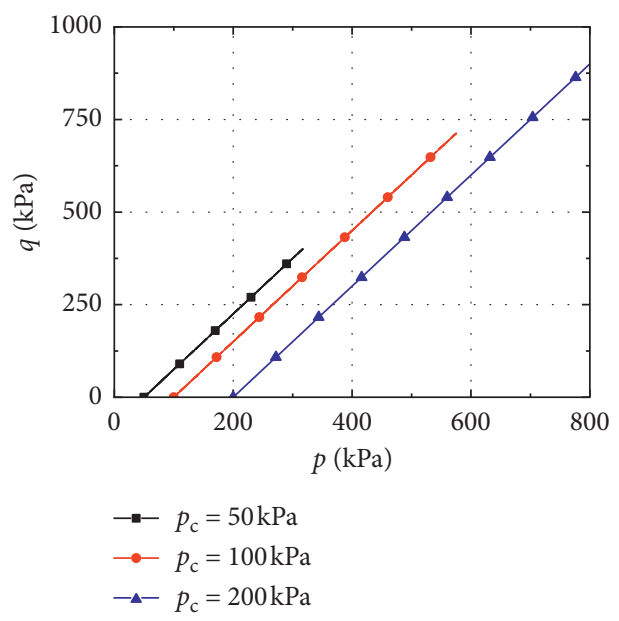

(c)

Figure 3: The designed stress path of the test. (a) The first group. (b) The second group. (c) The third group.

strain relationship under the same $b$ and different $p_{c}$ conditions, especially to focus on the variety of $u, p^{\prime}, q$, and $\eta$ to obtain the $3 \mathrm{D}$ deformation strength relationship, critical state line, and phase transition line of aeolian sand in Tengger Desert.

Figure 4 shows that the evolutions of the $b$-value in real time during the shearing process for all schemes. The data show that strain control loading can realize that the value of $b$ remains constant during the loading process.
4.2. The Strength and Deformation of Different $b$ at the Same Confining Pressure. Figure 5 shows that the $u-\varepsilon_{1}$ curves of the four $b$-values can be divided into two stages: the increasing and decreasing stages of $u$. The increasing of $u$ indicated that the specimen is compressed at the initial shearing stage and the void water volume inside the specimen is compressed. In the decreasing stages, the aeolian sand is excessively dilated from contraction to dilatation, and the void ratio of sand is increased, which lead to a drop 


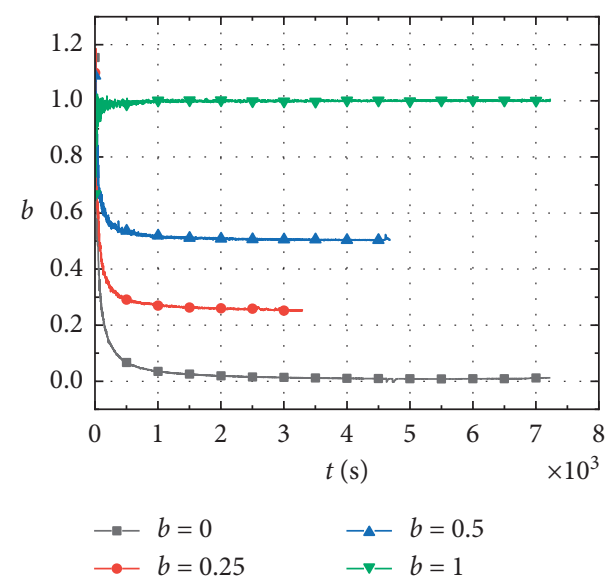

Figure 4: The measured value of stress path.

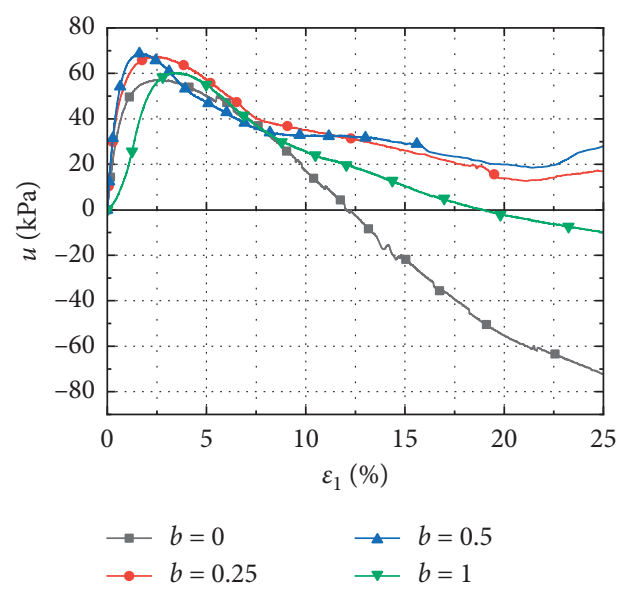

Figure 5: Change of void water pressure with different $b$-values at $p_{c}=100 \mathrm{kPa}$.

in void water pressure. The transition point from contraction to dilatation is focused around $\varepsilon_{1}=2.5 \%$. Except for $b=1$, the degree of dilatation after the state transition point showed a decreasing trend with the increase of $b$-value. The possible reason is that when $b=1$, the direction of $\sigma_{1}$ is in the horizontal direction of the specimen, and the anisotropy of the sand in these direction affects its dilatancy.

Figure 6(a) shows that all the stress-strain curves of different $b$-values show the shear hardening at $p_{c}=100 \mathrm{kPa}$ and $q$ gradually increases with the increase of $\varepsilon_{1}$. When $\varepsilon_{1}<10 \%$, all curves have the similar trend. But when $\varepsilon_{1} \geq 10 \%$, the curves affected by void water pressure and dilatancy are quite different. Figure 6(b) the relationships between $p^{\prime}$ and $q$ shows that the contraction decreases with the increase of $b$-value before the state transition point and then the curves tend to be straight after the point and the slope of the straight line increases. When $b=1$, the difference of the curves is related to the direction change of $\sigma_{1}$.
Figure 6(c) shows the same pattern for the stress ratio. With the increase of $\varepsilon_{1}, \eta$ increased rapidly before reaching a critical state and then $\eta$ reached stability. When $\varepsilon_{1}<5 \%$, the $b$-value has a greater effect on curves and the slope increases with the $b$-value increases.

\subsection{The Characteristics of the Critical State}

4.3.1. The Critical State Line and the State Transition Line of $b=0$. Figure 7 shows the changes of void water pressure under the conditions of different $p_{c}$ at $b=0$. On the whole, the trends of the void water pressure are increasing first and then decreasing; it means that the dense aeolian sand shows the pattern of first contraction and then dilatancy. Before the state transition point, the rate of void water pressure increases with the increase of $p_{c}$, and the contraction become more obvious. After the state transition point, the void water pressure decreases with the increase of $p_{c}$. When $p_{c}$ reaches $800 \mathrm{kPa}$, the decreasing trends of void water pressure are weakened. The positive value of void water pressure indicates that the dilatancy become more and more obvious.

Figure 8 (a) shows the stress-strain relationship of dense aeolian sand under the conditions of different $p_{c}$ at $b=0$. The curves are all hardened, and $q$ increased with the increase of $p_{c}$. The results in Figure 8(b) show that the curves of all different $p_{c}$ and the same $b$ tend to the same critical state, $q=1.57 p^{\prime}$. The state transition line from shear contraction to dilatancy under the undrained can be obtained as $q=1.23 p^{\prime}$. In Figure $8(\mathrm{c})$, the relationships of $\eta-\varepsilon_{1}$ can obtain the same $\eta$ of 1.57 , which is the same as the critical state line.

4.3.2. The Critical State Line and the State Transition Line of $b=1$. Figure 9 shows the changes of void water pressure of dense aeolian sand under conditions of different $p_{c}$ when $b=1$. The void water pressure is shown a trend of increasing first and then decreasing. However, the increase is greater than that in Figure 7, which indicates that the contraction of $b=0$ is stronger than that of $b=1$ at the same $p_{c}$. When $p_{c}$ reaches $200 \mathrm{kPa}$, void water pressure is a positive value. Dense aeolian sand shows a shear contraction characteristic.

Figure 10(a) shows the stress-strain relationship of dense aeolian sand under the conditions of different $p_{c}$ at $b=1$. The curves are still hardened, and the generalized shear stress increases with the increase of $p_{c}$, but the hardened trend is weaker than that in Figure $8(a)$ at the same $p_{c}$ and $b=0$. The results in Figure 10(b) show that all curves tend to the same critical state line and the same state transition line, and they are $q=1.24 p^{\prime}$ and $q=1.04 p^{\prime}$. Compared with Figure $8(\mathrm{~b})$, the critical state line and the state transition line are significantly smaller than those at $b=1$. In Figure $10(\mathrm{c})$, the curves between the stress ratio and the large principal strain can obtain the same stress ratio of 1.24 , which is the same critical state line. 


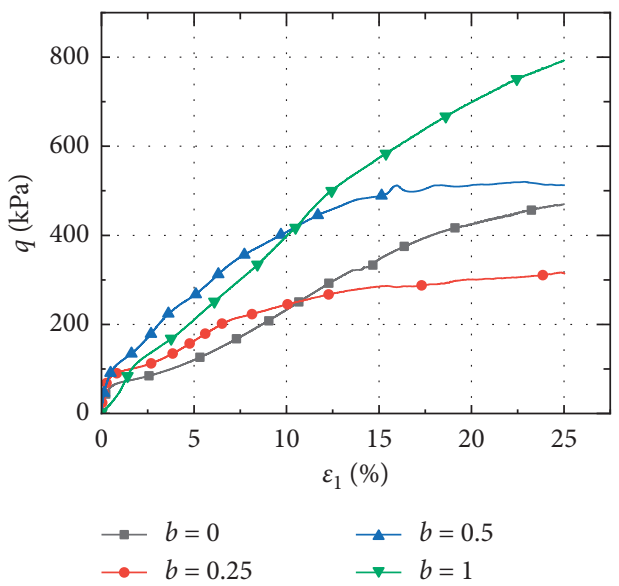

(a)

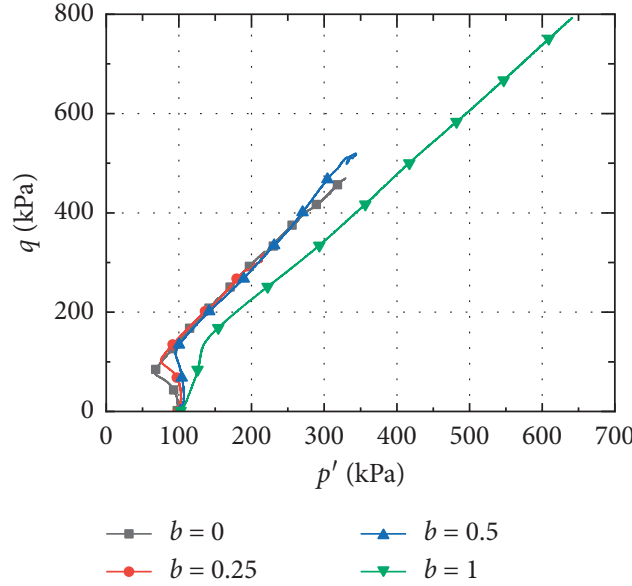

(b)

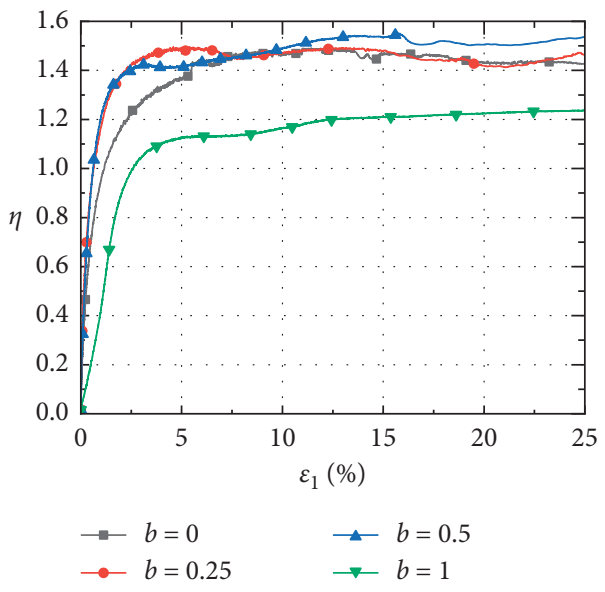

(c)

Figure 6: Stress-strain relationships of different $b$-values at $p_{c}=100 \mathrm{kPa}$. (a) Relationships of $q-\varepsilon_{1}$. (b) Relationships of $p^{\prime}-q$. (c) Relationships of $\eta-\varepsilon_{1}$.

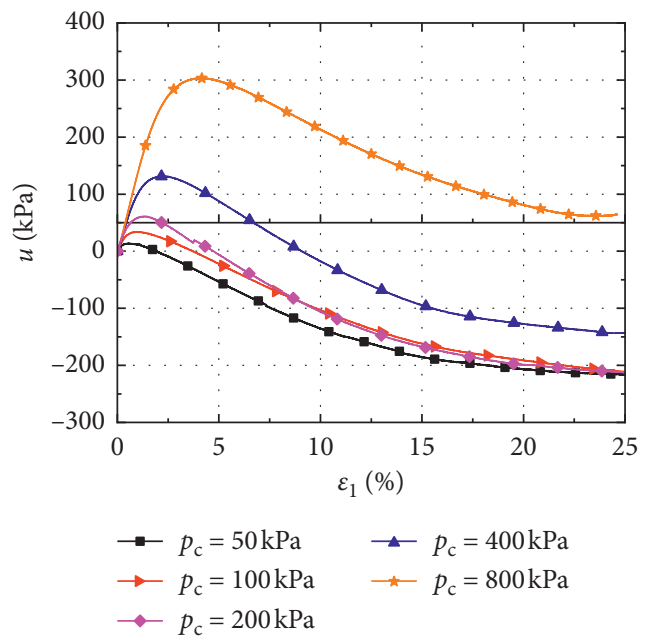

Figure 7: The variation of void water pressure at $b=0$. 


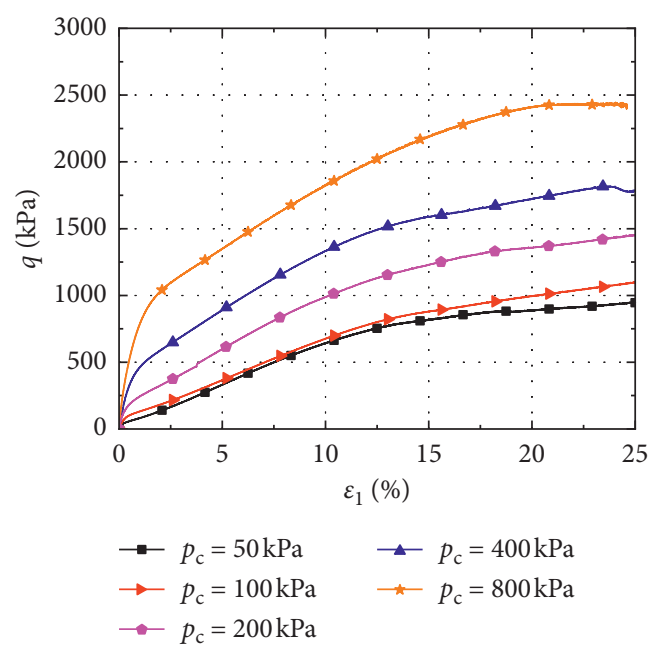

(a)

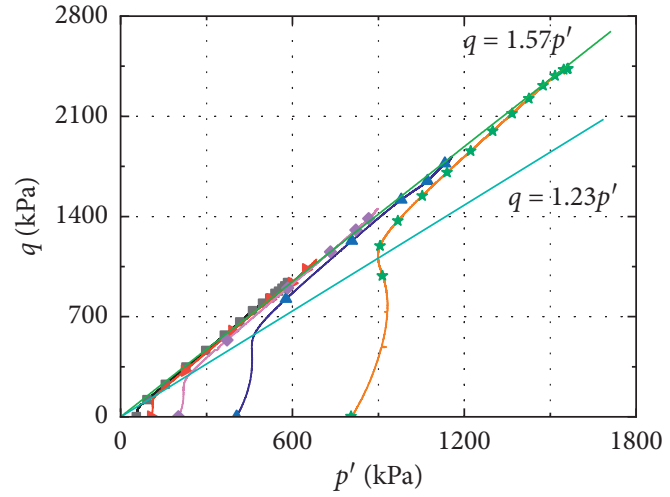

$\rightarrow p_{\mathrm{c}}=50 \mathrm{kPa} \rightarrow p_{\mathrm{c}}=400 \mathrm{kPa}$
$\rightarrow p_{\mathrm{c}}=100 \mathrm{kPa} \rightarrow p_{\mathrm{c}}=800 \mathrm{kPa}$
$\rightarrow p_{\mathrm{c}}=200 \mathrm{kPa}$

(b)

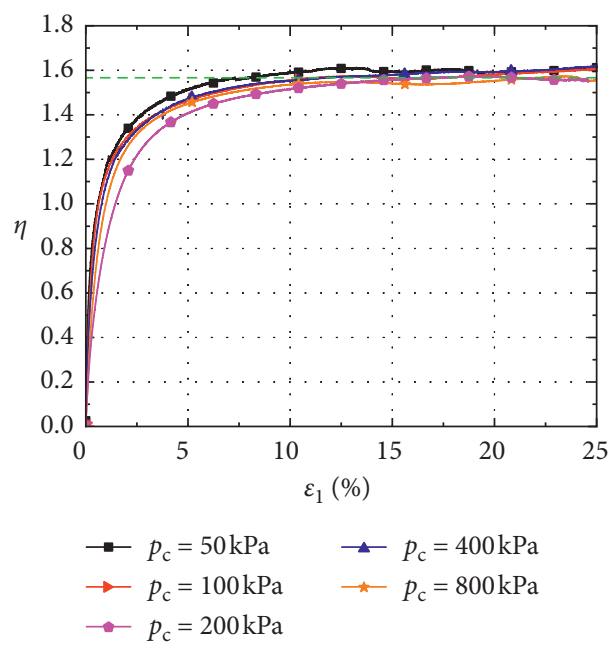

(c)

FiguRE 8: Stress-strain relationship and critical state line at $b=0$. (a) The stress-strain relationships. (b) The critical state line and the state transition line in $p^{\prime}-q$ space. (c) The critical state line of stress ratio and strain space.

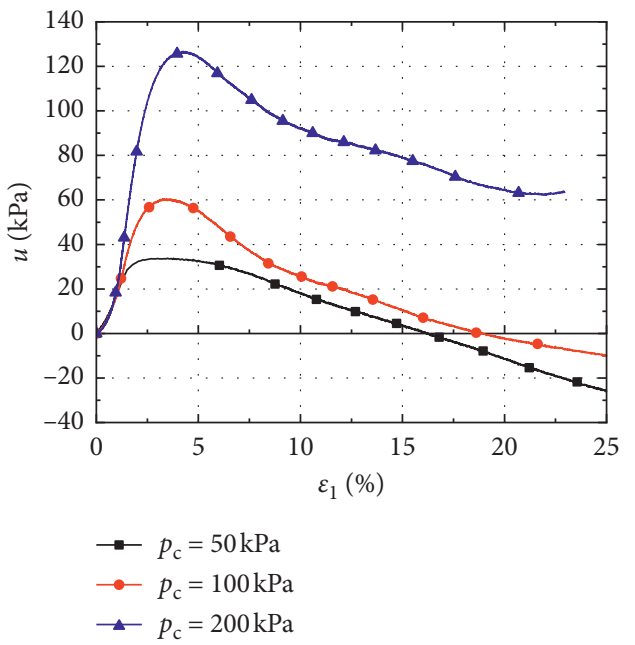

FIGURE 9: The variation of void water pressure at $b=1$. 


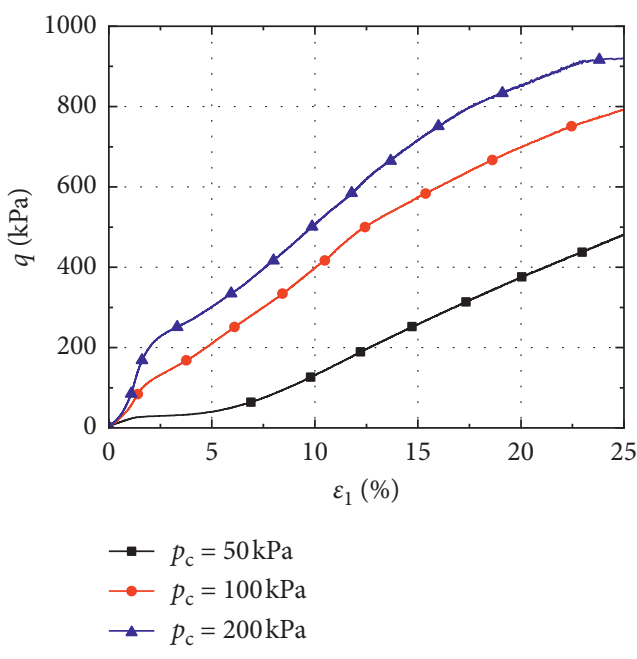

(a)

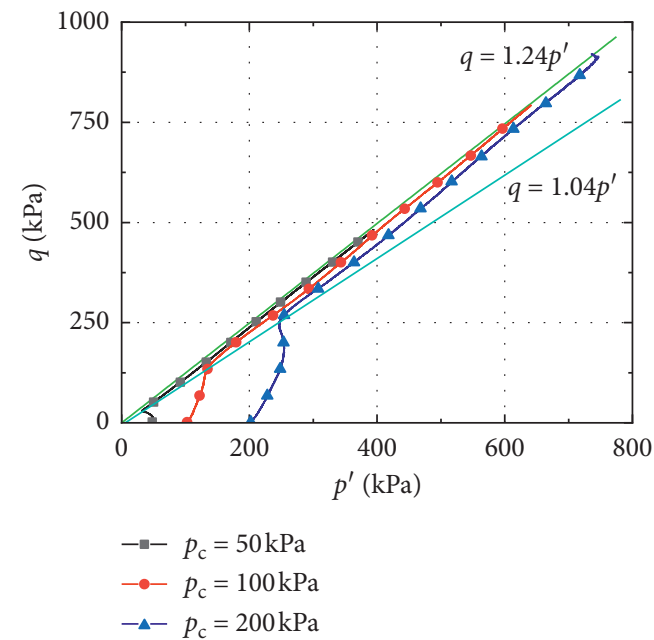

(b)

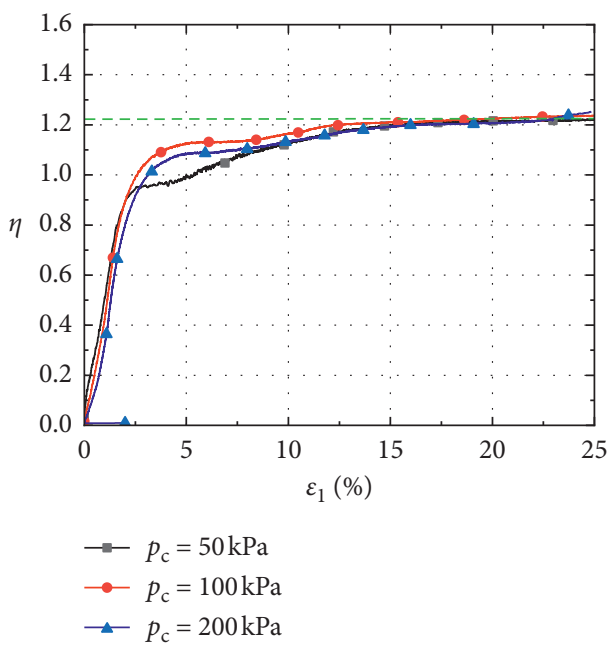

(c)

Figure 10: The stress-strain relationships and the critical state line at $b=1$. (a) The stress-strain relationships. (b) The critical state line and the state transition line in $p^{\prime}-q$ space. (c) The critical state line of stress ratio.

\section{Conclusions}

In order to make up the shortage of experimental data for aeolian sand in Tengger Desert, this paper obtains the critical state line and state transition line of aeolian sand under different $3 \mathrm{D}$ stress path conditions, as well as different $b$ values at the same $p_{c}$. To grasp the true $3 \mathrm{D}$ mechanical properties of dense aeolian sand, a series of undrained tests were carried out using the British GDS true triaxial test system. The main conclusions are as follows:

(1) The test adopts the strain control method, which realizes the constant $b$-value of proportional stress loading by controlling the middle principal strain coefficient and verifies the accuracy of the strain control by real-time monitoring of the $b$-value.
(2) The results of different $b$-values at the same $p_{c}$ show that the dilatancy of dense aeolian sand increased with the $b$-value according to the change of void water pressure. In $p^{\prime}-q$ space and $\eta-\varepsilon_{1}$ space, the strength of aeolian sand increases with the $b$-value, which is consistent with the test design. When $b=1$, the direction of the maximum principal stress is changed to the horizontal direction, and the stressstrain relationships are consistent with the design, which indicates that it is greatly influenced by anisotropy.

(3) Two commonly used limit state lines in geotechnical engineering are obtained from the test. The critical state line and phase transition line are obtained with the same $b$-value and different $p_{c}$. When $b=0$, the 
critical state line and phase transition line are greater than $b=1$, and the rules of dilatancy are relatively stable. The results fully confirm the purpose of the test design and provide the data for geotechnical engineering design, construction, and maintenance in the Tengger Desert area.

$\begin{array}{ll}\text { Abbreviations } \\ b \text { or } b \text { - } & \text { Intermediate principal stress coefficients } \\ \text { value: } & \\ q: & \text { Generalized shear stress }(\mathrm{kPa}) \\ P: & \text { Mean principal stress }(\mathrm{kPa}) \\ p_{c}: & \text { Effective confining pressure during } \\ p^{\prime}: & \text { Consolidation }(\mathrm{kPa}) \\ B: & \text { Effective mean principal stress }(\mathrm{kPa}) \\ \sigma_{1}: & \text { Void water pressure coefficient } \\ \sigma_{2}: & \text { Maximum principal stress }(\mathrm{kPa}) \\ \sigma_{3}: & \text { Intermediate principal stress }(\mathrm{kPa}) \\ b_{\varepsilon}: & \text { Minimum principal stress }(\mathrm{kPa}) \\ \varepsilon_{1}: & \text { Intermediate principal strain coefficient } \\ \varepsilon_{2}: & \text { Maximum principal strain } \\ \varepsilon_{3}: & \text { Intermediate principal strain } \\ \varepsilon_{v}: & \text { Minimum principal strain } \\ \mathrm{d} \varepsilon_{1}: & \text { Volume strain } \\ \mathrm{d} \varepsilon_{2}: & \text { The increment of maximum principal strain } \\ \mathrm{d} \varepsilon_{3}: & \text { The increment of intermediate principal strain } \\ \eta: & \text { The increment of minimum principal strain } \\ u: & \text { Stress ratio } \\ t: & \text { Void water pressure (kPa) } \\ & \text { Time (s). }\end{array}$

\section{Data Availability}

The data used to support the findings of this study are available from the corresponding author upon request.

\section{Conflicts of Interest}

The authors declare that there are no conflicts of interest regarding the publication of this paper.

\section{Acknowledgments}

This work was financially supported by the Key R\&D Program of Ningxia Hui Autonomous Region Projects of International Cooperation and Exchanges (No. 2018DWHZ0084), the National Key R\&D Program of China (No. 2017YFC0504404), and the Projects for Leading Talents of Science and Technology Innovation of Ningxia (No. KJT2019001), and these supports are gratefully acknowledged.

\section{References}

[1] H. Xie, F. Ma, and S. Wu, "Numerical simulation of sand transport around the highway in sandy desert area," Journal of Desert Research, vol. 39, no. 2, pp. 151-157, 2019.
[2] Y. Feng, Compaction Technology Study of Tengger Desert Aeolian Sand Subgrade, Chang'an University, Xi'an, China, 2017.

[3] M. Li, L. Chen, and W. Chen, "The moisture problem of sandfixing afforestation in Zhongwei section along Bao Lan railway in Tengger Desert," Chinese Science Bulletin, vol. 8, pp. 249-251, 1958.

[4] C. Liu, G. Wu, Y. Zhang, and Y. Yang, "Research on features and compaction coefficient of subgrade aeolian sand filling for heavy haul railway in Mu Us Desert," Subgrade Engineering, vol. 6, pp. 138-142, 2016.

[5] W. Ma, "The engineering characteristics of silt-sand foundation in Tengeli Desert Zone," China Rural Water and Hydropower, vol. 11, pp. 74-77, 2004.

[6] Z. Zeng, M. Zhang, Z. Liang, and F. Shan, "Engineering geological features of eolian deposit sandy soil ground at southern edge of the Tenggeli Desert," Northwest Water Power, vol. 3, pp. 18-20, 2001.

[7] H. Che and Y. Zhu, "Experimental study of strengthening technology for a tunnel constructed in Aeolian sand stratum," Chinese Journal of Rock Mechanics and Engineering, vol. 3, pp. 206-213, 1993.

[8] Y. Yuan and X. Wang, "Experimental research on compaction characteristics of Aeolian sand," Chinese Journal of Geotechnical Engineering, vol. 29, no. 3, pp. 360-365, 2007.

[9] Z. Li, Y. Cao, N. Liang, and Y. Mei, "Compaction mechanism of aeolian sand," China Journal of Highway and Transport, vol. 19, no. 5, pp. 6-11, 2006.

[10] C. Xue, H. Li, and B. Hu, "Mechanical analysis on the new type of semi-rigid asphalt pavement structure based on dynamic parameters," Highways, vol. 6, pp. 20-24, 2013.

[11] Z. Zeng, M. Zhang, and M. Huang, "A study on the collapsibility of aeolian sand in the southern margin of Tengger Deserts," Journal of Gansu Sciences, vol. 2, pp. 63-68, 2000.

[12] J. Su, "Study on collapsibility of sandy soil for desert sand," Geotechnical Engineering World, vol. 4, no. 8, pp. 27-29, 2001.

[13] Q. Wang, Y. Liu, X. Fu, and W. Ren, "Reliability analysis for wetting deformation and stability of sand soil roadbed," China Journal of Highway and Transport, vol. 20, no. 6, pp. 7-12, 2007.

[14] X. Lü, M. Huang, and J. Qian, "The onset of strain localization in cross-anisotropic soils under true triaxial condition," Soils and Foundations, vol. 51, no. 4, pp. 693-700, 2011.

[15] X. Lü, M. Huang, and J. Qian, "Influences of loading direction and intermediate principal stress ratio on the initiation of strain localization in cross-anisotropic sand," Acta Geotechnica, vol. 13, no. 3, pp. 619-633, 2017.

[16] X. Li, Z. Ma, W. Lu, and Y. Wang, "True-triaxial drained test of Tengger Desert sand," Advances in Civil Engineering, vol. 2020, Article ID 8851165, 11 pages, 2020.

[17] Y. Deng, X. Li, Wang, Y. Song, and J. Peng, "Study on dynamic strength of the Aeolian sand in Maowusu Desert area," Engineering Mechanics, vol. 29, no. 12, pp. 281-286, 2012.

[18] Y. Song, Test Study on the Mechanical Property of the Aeolian Sand and the Bearing Capacity of the Aeolian Sand Ground of Mu Us Desert, Chang'an University, Xi'an, China, 2011.

[19] X. Zhang, J. Li, F. Yi, Q. Sun, Z. Qu, and Y. Hu, "Dynamic tests and damage mechanism of frozen aeolian soil in western Liaoning area of China," Chinese Journal of Geotechnical Engineering, vol. 40, no. 2, pp. 370-377, 2018.

[20] S. Zhang, C.-A. Tang, X.-D. Zhang, Z.-C. Zhang, and J.-X. Jin, "Cumulative plastic strain of frozen aeolian soil under highway dynamic loading," Cold Regions Science and Technology, vol. 120, pp. 89-95, 2015. 
[21] J. Li, F. Wang, F. Yi, F. Wu, J. Liu, and Z. Lin, "Effect of freezethaw cycles on triaxial strength property damage to cement improved aeolian sand (CIAS)," Materials, vol. 12, no. 17, 2019.

[22] J. Li and Y. Zhang, "Undrained monotonic and dynamic triaxial properties of the aeolian sand," Earth and Environmental Science, vol. 242, no. 6, 2019.

[23] H. Yong, W. Li, and Q. Yu, "A test study on the impact of dry density and water content on the structural strength index of intact unsaturated aeolian soil," Electronic Journal of Geotechnical Engineering, vol. 20, pp. 1933-1945, 2015.

[24] M. Badanagki, Shear Strength and Stiffness of a Sahara Sand from Libya, Colorado State University, Fort Collins, CO, USA, 2011.

[25] C. Choi, A. Pedro, and D. Michael, "Development of a true triaxial apparatus for sands and gravels," Geotechnical Testing Journal, vol. 31, no. 1, pp. 32-44, 2008.

[26] L. Suits, T. Sheahan, L. Ibsen, and U. Prasstrup, "The Danish rigid boundary true triaxial apparatus for soil testing," Geotechnical Testing Journal, vol. 25, no. 3, pp. 254-265, 2002.

[27] P. Lade and Q. Wang, "Analysis of shear banding in true triaxial tests on sand," Journal of Engineering Mechanics-asce, vol. 127, no. 8, 2001

[28] Y. Yamada and K. Ishïhara, "Undrained deformation characteristics of loose sand under three-dimensional stress conditions," Soils and Foundations, vol. 21, no. 1, pp. 97-107, 1981.

[29] M. Yoshimine, K. Ishihara, and W. Vargas, "Effects of principal stress direction and intermediate principal stress on undrained shear behavior of sand," Soils and Foundations, vol. 38, no. 3, pp. 179-188, 1998.

[30] K. Pan, Z. Yang, and T. Xu, "Impact of static preshearing on undrained anisotropy and shear characteristics of sand," International Journal of Geomechanics, vol. 18, no. 12, pp. 112,2018

[31] C. Xu, M. Luan, Y. He, Y. Guo, and M. Li, "Effect of intermediate principal stress on undrained behavior of saturated loose sands under monotonic shearing," Rock and Soil Mechanics, vol. 5, pp. 689-693, 2006.

[32] J. Li and X. Yang, "The strength properties of the coarse sand with various fine sand contents," Soil Eng. and Foundation, vol. 30, no. 6, pp. 721-725, 2016.

[33] T. G. Murthy, D. Loukidis, J. A. H. Carraro, M. Prezzi, and R. Salgado, "Undrained monotonic response of clean and silty sands," Géotechnique, vol. 57, no. 3, pp. 273-288, 2007.

[34] P. Hu, M. Huang, S. Ma, and X. Lü, "True triaxial tests and strength characteristics of silty sand," Rock and Soil Mechanics, vol. 322, pp. 465-470, 2011.

[35] M. Liang and H. Ping, "True triaxial tests and strength characteristics study on silty sand," in Proceedings of the 2017 2nd International Conference on Test, Measurement and Computational Method, TMCM, Beijing, China, May 2017.

[36] Y. Wu, J. Cui, J. Huang, W. Zhang, N. Yoshimoto, and L. Wen, "Correlation of critical state strength properties with particle shape and surface fractal dimension of clinker ash," International Journal of Geomechanics, vol. 21, 2021.

[37] X. Li and Y. F. Dafalias, "Anisotropic critical state theory: role of fabric," Journal of Engineering Mechanics, vol. 138, no. 3, pp. 263-275, 2011.

[38] A. Sadrekarimi and S. M. Olson, "Residual state of sands," Journal of Geotechnical and Geoenvironmental Engineering, vol. 140, no. 4, 2013

[39] Y. Wu, N. Li, and X. Wang, "Experimental investigation on mechanical behavior and particle crushing of calcareous sand retrieved from South China Sea," Engineering Geology, vol. $280,2021$.

[40] ASTM2487, Standard Practice for Classification of Soils for Engineering Purpose (Unified Soil Classification System), ASTM, West Conshohocken, PA, USA, 2017. 